\title{
Resistance Spot Welding between Steel and Aluminum Alloy Lihu Cui ${ }^{\mathrm{a}, 1}$, Ranfeng Qiu ${ }^{\mathrm{b}, 1,2}$, LongLong Hou ${ }^{1}$, Zhongbao Shen ${ }^{1}$, Qingzhe $\mathrm{Li}^{1}$ \\ 1. School of Materials Science and Engineering, Henan University of Science and Technology, Luoyang, 471003, China \\ 2. Collaborative Innovation Center of Nonferrous Metals, Luoyang 471003, China \\ ahekeda131@126.com, bqiurf1221@163.com
}

KEYWORD: Aluminum alloy; Mild steel; Resistance spot welding

ABSTRACT: Aluminum alloy A6061 and mild steel Q235 sheets were welded by resistance spot welding. The interfacial microstructure was observed and the feature and distribution of the interfacial reactant were analyzed and the effects of welding current on the nugget size and tensile shear strength of the joint were investigated. The results indicate that both the tensile shear strength and nugget diameter of the joint increase with the increasing of welding current in some degree. When welding current exceeds a certain range, the nugget diameter of the joint tends towards stability and the tensile shear strength decreases. The joint with the maximum tensile shear load of $1.5 \mathrm{kN}$ is obtained at the condition of $12 \mathrm{kA}$ welding current. The interfacial reaction layer thickness decreased from central joints region to surrounding area.

\section{Introduction}

In automotive industry, weight reduction is strongly demanded for energy and natural resource savings. From the perspective of material supply, aluminum alloy and steel is the most important of the materials in the automotive lightweight. Therefore, the achievement of a sound joining technique between aluminum alloy and steel is indispensable. On the other hand, resistance spot welding is a widely used and important welding process in the fields of automotive manufacturing because it is economical, fast, and robust to part tolerance variations. Therefore, the resistance spot welding of aluminum alloy has been widely investigated recently. However, the resistance spot welding between the two kinds of materials accompanies some difficulties, because of the large difference in physical and thermal properties between aluminum alloy and steel, and the formation of brittle reaction products at the welding interface ${ }^{[1-3]}$. Hence, solid state welding methods have been studied in the last few years to acquire a sound joint, such as explosion welding ${ }^{[4]}$, diffusion welding ${ }^{[5]}$, friction stir welding ${ }^{[6]}$. Although the joints obtained by the above means show reasonable performance to a certain extent, the joint shape and size are restrained by equipment configuration and capacity.

In this study, aluminum alloy A6061 and mild steel Q235 was welded using resistance spot welding. The effects of welding parameters on properties of the joint were analyzed, and provide some fundamental information for improving mechanical properties of the joint between aluminum alloy and mild steel.

\section{Experimental Materials and Methods}

\section{Experimental Materials}

The materials used in this study were $1.0 \mathrm{~mm}$ thick plates of aluminum alloy A6061 and mild steel Q235. The specimen geometry is $100 \mathrm{~mm} \times 30 \mathrm{~mm} \times 1 \mathrm{~mm}$. Their chemical compositions are listed in Table 1. 
Table1. Chemical composition of materials (Mass \%)

\begin{tabular}{lllllllllllll}
\hline & $\mathrm{Cr}$ & $\mathrm{Cu}$ & $\mathrm{Ti}$ & $\mathrm{Mg}$ & $\mathrm{V}$ & $\mathrm{C}$ & $\mathrm{P}$ & $\mathrm{S}$ & $\mathrm{Si}$ & $\mathrm{Mn}$ & $\mathrm{Fe}$ & $\mathrm{Al}$ \\
\hline $\mathrm{A} 6061$ & 0.04 & 0.3 & 0.15 & 1.0 & - & - & - & - & 0.6 & 0.15 & - & Bal. \\
Q235 & - & - & - & - & 0.06 & 0.14 & 0.04 & 0.02 & 0.4 & 1.0 & Bal. & - \\
\hline
\end{tabular}

\section{Experimental Methods}

The schematic diagram of resistance spot welding between steel and aluminum alloy is shown in Figure 1.

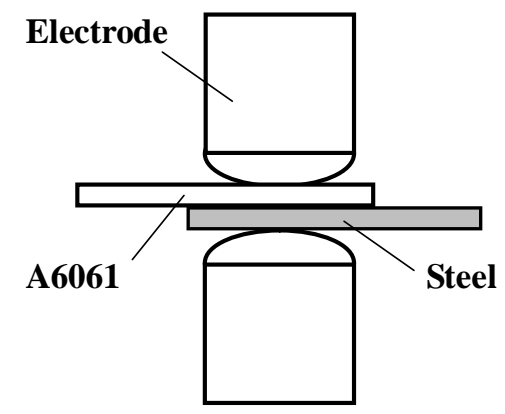

Figure 1. Schematic diagram of resistance spot welding

Fig. 2 shows the shape and size of joint. The welding current was changed every $1 \mathrm{kA}$ between 8 and $14 \mathrm{kA}$ at the fixed electrode force of $2105 \mathrm{~N}$ and welding time of 10 cycles. The interfacial microstructure was observed using scanning electron microscope (SEM). In order to examine the mechanical properties of the joints, the tensile-shear tests were performed under a cross-head velocity of $1.7 \times 10^{-5} \mathrm{~m} / \mathrm{s}$ at room temperature.

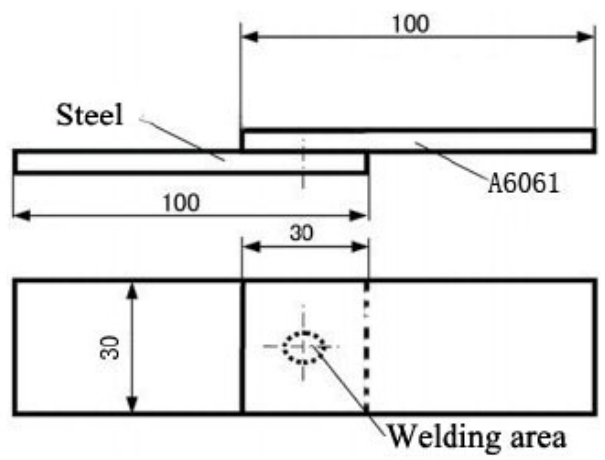

Figure 2. Shape and size of specimen for welding

\section{Results and Discussion}

Microstructural analysis of A6061/Q235 interface

Fig. 3 shows macroscopic cross-section appearance of the A6061/Q235 joint, which welded at the condition of welding current of 14 kA. Fig. 4 (a), (b) and (c) show SEM image of the location A、B and $\mathrm{C}$ in Fig. 3, respectively. 


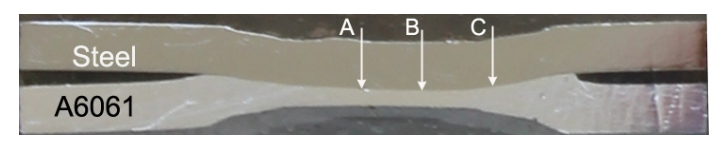

Figure 3. Appearance of cross-section of welded joint

As shown in Fig. 4, the formation of reaction layer was observed at the welding interface. However, the thickness of reaction layer is various at welding interface. Its thickness in the nugget center area reaches to the maximum. As far from the nugget center area, the thickness of interfacial reaction layer becomes thin. And the continuous reaction layer transfer to discontinuous distribution of reactants gradually.

The distribution of interfacial reaction layer thickness related to the reaction temperature field in welding process ${ }^{[7]}$. The center nugget of spot welding joints produced the most heat and cooled slow. In contrast, the nugget edges produced less heat and cooled fast. Therefore, the nugget center had high energy. Temperature outside the central area of nugget was far lower than the nugget center, where the reaction time is shorter than in the central nugget region. The reaction layer thickness $(\mathrm{X})$ is a function of reaction time $(\mathrm{t})$ and temperature $(\mathrm{T})$, which is determined by the equation (1). As we can see from the equation (1), the reaction layer thickness (X) decreased from central joints region to surrounding area.

$\mathrm{X}=(2 \mathrm{Kt})^{1 / 2}$

In the formulas:

$\mathrm{K}=\mathrm{K}_{0} \exp (-\mathrm{Q} / \mathrm{RT})$ - Growth factor

$\mathrm{K}_{0}$ - Factor

$\mathrm{R}$ - Gas constant

$\mathrm{Q}$ - Growth activation energy of reaction laye
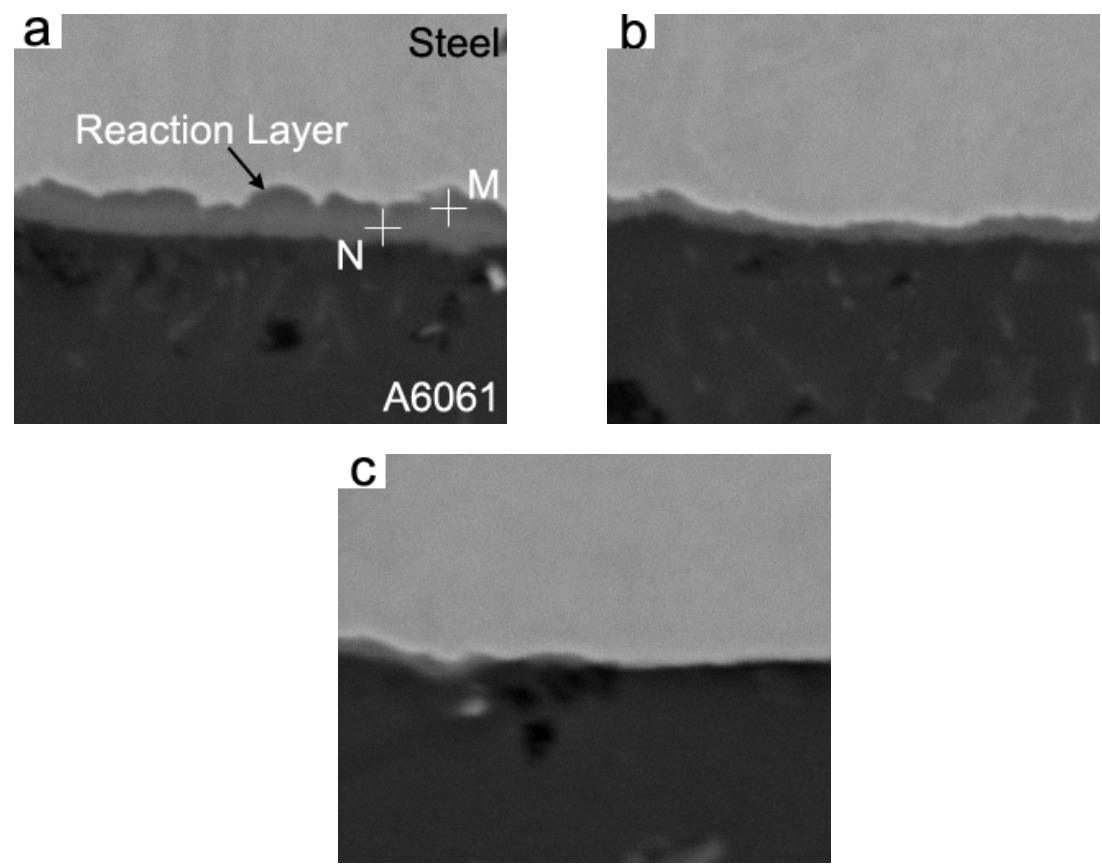

Figure 4. SEM micrographs showing microstructure of aluminum and steel interface (Figure a, b, c correspond to areas of A, B, C in Fig. 3, respectively)

In Fig. 4 (a), the formation of reaction layer was observed at the welding interface. In Q235 side, the interface bumped up and down between reaction layer and steel. In A6061 side, the micro-projections were observed at the junction of the reaction layer and aluminum. Position $\mathrm{M}$ and $\mathrm{N}$ nears to Q235 and A6061 respectively. M and N two points' energy dispersive spectrometer (EDS) analysis results show in Table 2 .

In Table 2, the atomic ratio of aluminum and iron is 3.38 on the position $\mathrm{M}$ and 2.43 on the 
position N. According to Fe-Al binary phase diagram ${ }^{[8]}$ and intermetallic compound species analysis of aluminum and steel, the reaction layer product on the side of aluminum is $\mathrm{FeAl}_{3}$ and the reaction layer product on the side of steel is $\mathrm{Fe}_{2} \mathrm{Al}_{5}$.

Table 2. EDS analysis results of interfacial intermetallic layer in Fig4. (a) (at\%)

\begin{tabular}{ccc}
\hline Location & $\mathrm{Fe}$ & $\mathrm{Al}$ \\
\hline $\mathrm{M}$ & 22.80 & 77.20 \\
$\mathrm{~N}$ & 29.10 & 70.90 \\
\hline
\end{tabular}

\section{Effect of welding parameters on mechanical properties of joints}

Fig. 5 and 6 shows the effects of welding current on the nugget diameter and tensile shear load of joint, respectively. Welding current is the main factors influencing the resistance heat. In Fig. 5, the nugget diameter firstly increased with the welding current increasing, and then tended to a constant date with the welding current further increasing. According to Joule's law, the heat production increases along with the increase of welding current, so it can generate large nugget. However, nugget diameter tends to stability finally when welding current increases to a certain degree. This is because the growth of nugget was limited to the electrode size.

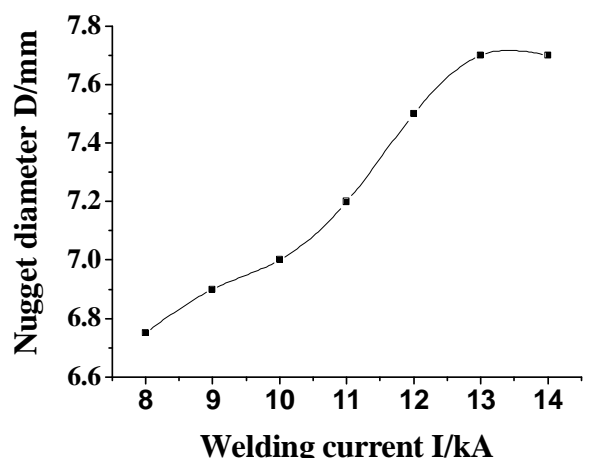

Figure 5. Effect of welding current on nugget diameter

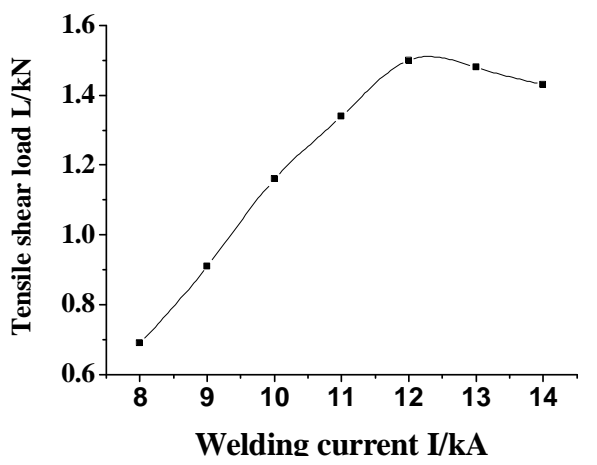

Figure 6. Effect of welding current on tensile shear load

As shown in Fig. 6, with the welding current increasing, the tensile shear load firstly increased and then decreased. The maximum tensile shear load reached $1.5 \mathrm{kN}$ at $12 \mathrm{kA}$ welding current. This is because the tensile shear load of the joint is influenced by nugget size and thickness of the intermetallic compound formed at the welding interface. In the low current range, the impact of nugget size on the tensile shear load is greater than the latter, whereas the thickness of intermetallic compound plays a major role in the high current range. 


\section{Conclusion}

1. With the increase of welding current, the nugget diameter of joint increased, and the shear load firstly increased then decreased.

2. The interfacial reaction layer thickness decreased from central joints region to surrounding area.

3. The joint with the maximum tensile shear load of $1.5 \mathrm{kN}$ is obtained at the condition of $12 \mathrm{kA}$ welding current.

\section{Acknowledgement}

This work was supported by the Natural Science Foundation of China (grant no. U1204520), Henan Province Foundation and Advanced Technology Research Program (grant no. 122300410202), Henan Province College \& University Youth Backbone Teachers Found Project (grant no. 2013GGS-064); Natural Science Innovation Ability Cultivating Project of Henan University of Science and Technology (2014ZCX003); National Training Programs of Innovation and Entrepreneurship for Undergraduates (201310464023) and the project sponsored by SRF for ROCS, SEM.

\section{References}

[1] Ranfeng Qiu, Shinobu Satonaka, Chihiro Iwamoto, Effect of interfacial reaction layer continuity on the tensile strength of resistance spot welded joints between aluminum alloy and steels, Materials and Design. 30 (2009) 3686-3689.

[2] Nan Wang, Tomiko Yamaguchi and Kazumasa Nishio, Interfacial microstructure and strength of aluminum alloys/steel spot welded joints, J. Japan Inst. Met. Mater. 2013, 77(7), 259-267.

[3] Weihua Zhang, Daqian Sun, Lijun Han, Wenqiang Gao and Xiaoming Qiu, Characterization of intermetallic compounds in dissimilar material resistance spot welded joint of high strength steel and aluminum alloy, ISIJ International, 2011, 51, (11), 1870-1877.

[4] Benák, M.; Turna, M.; Palcek, P.; Nesvadba, P. Study of explosion welding of Mg alloy with aluminum, Defect and Diffusion Forum, v 297-301, p 1177-1182, 2010, Diffusion in Solids and Liquids $\mathrm{V}$

[5] Bulkov, A.K. ; Peshkov, V.V.; Petrenko, V.R.; Balbekov, D.N. Stryguin, A.I. Effect of technological parameters on the process of diffusion welding of titanium, Welding International, v 28, n 3, p 222-227, March 2014

[6] Zhang, Teng; He, Yu Ting; Shao, Qing; Hou, Bo; Gao, Chao, Study on residual stresses and fatigue properties of friction stir welding joint, Advanced Materials Research, v 884-885, p 374-377, 2014, Biotechnology, Chemical and Materials Engineering III

[7] Eiazadeh H, HamediM, Halvaee A, et al. New parametric study of nugget size in resistance spot welding process using finite element method [J].Materials and Design, 2010, 31(1):149-157

[8]Shahverdi H R, Ghomanshchi M R. Shabestari S, et al. Microstructure analysis of interfacial reaction between molten aluminium and solid iron [J]. Journal of Materials Processing Technology, 2002, 124 (6): 345-352 